\title{
VALOR NUTRITIVO DE SILAGENS DE SEIS CULTIVARES DE GIRASSOL EM DIFERENTES IDADES DE CORTE ${ }^{1}$
}

\author{
Nutritive value of six cultivars of sunflower silages at different cutting ages
}

\author{
Adauton Vilela de Rezende ${ }^{2}$, Antônio Ricardo Evangelista ${ }^{3}$, Alexandre Rocha Valeriano ${ }^{4}$, Gustavo Rezende Siqueira ${ }^{5}$, \\ Hélio Henrique Vilela ${ }^{6}$, Jalison Lopes ${ }^{5}$
}

\begin{abstract}
RESUMO
Características agronômicas e bromatológicas de seis cultivares de girassol (Helianthus annuus L.), colhidas aos 95 e 110 dias após a semeadura, foram avaliadas para produção de silagem. Utilizaram-se os híbridos Cargill C 11, Braskallb DK 180, Braskallb DK 4040, Morgon M 92007, Morgon M 742 e a variedade V 2000 da EMBRAPA. O delineamento foi o de blocos casualizados, com quatro repetições, em esquema fatorial 2 × 6, sendo considerados como fatores a idade de corte e as cultivares. As plantas foram picadas mecanicamente em partículas de 2,0 a 3,0 cm de tamanho e ensiladas por 30 dias em silos de "PVC" com dez centímetros de diâmetro e quarenta centímetros de comprimento. Avaliaram-se as produções e os teores de matéria seca (MS), concentrações de proteína bruta $(\mathrm{PB})$, extrato etéreo (EE), fibra em detergente neutro (FDN) e os valores de digestibilidade "in vitro" da matéria seca (DIVMS) e de pH das silagens. A maior produção de MS foi de 11,27 t/ha, enquanto a menor foi de 4,88 t/ha, respectivamente, das cultivares M 92007 e V 2000. Em relação a todas as características avaliadas das silagens, observou-se diferença significativa entre as duas idades de corte utilizadas. As cultivares apresentaram comportamento distinto para cada idade de corte analisada. Os resultados permitiram concluir que ocorrem diferenças bromatológicas nas silagens em função das cultivares e da idade de corte utilizada.
\end{abstract}

Termos para indexação: Helianthus annuus, maturação, qualidade, rendimento.

\begin{abstract}
Agronomic and chemical characteristics of six cultivars of sunflower (Helianthus annus L.) harvested at 95 and 110 days after sowing, were evaluated for silage production. The hybrids Cargill C 11, Braskallb DK 180, Braskallb DK 4040, Morgon M 92007, Morgon M 742 and the variety V 2000 of EMBRAPA were studied. The experimental design used was a randomized complete block with four replications, in $2 \times 6$ factorial arrangement, being considered as factors cutting age and cultivars. Plants were mechanically chopped to reach 2.0 to $3.0 \mathrm{~cm}$ of particle size and ensiled for 30 days in PVC silos with ten centimeters of diameter and forty centimeters of length. Dry matter (DM) yield and content of moisture, crude protein (CP), ether extract (EE), neutral detergent fiber (NDF), values of "in vitro" dry matter disappearance (IVDMD) and $\mathrm{pH}$ of silages were measured. The highest dry matter production was $11.27 \mathrm{t} / \mathrm{ha}$, and the lowest $4.88 \mathrm{t} / \mathrm{ha}$, respectively, for the cultivars M-92007 and V2000. Based on analyzed characteristics of silages, a significant difference was observed between the two cutting ages tested. Cultivars showed different performance at each cutting age. In general, based on results it may be concluded that chemical differences in silages were related to the sunflower cultivars and cutting ages.
\end{abstract}

Key words: Helianthus annuus, maturation, quality, dry matter yield.

(Recebido em 4 de novembro de 2005 e aprovado em 6 de março de 2006)

\section{INTRODUÇÃO}

Diversas gramíneas e leguminosas podem ser empregadas para a produção de silagem. Dentre as gramíneas, o milho e o sorgo têm sido as mais utilizadas devido, principalmente, à facilidade de cultivo e aos altos rendimentos de matéria seca (MS) e de carboidratos solúveis. Entretanto, algumas culturas alternativas podem ser utilizadas para a confecção de silagem, dentre elas o girassol (Helianthus annuus L.).
A duração do ciclo de produção do girassol para a silagem é de 90 e 130 dias para as cultivares precoces e tardias, respectivamente (GONÇALVES et al., 1996). O ciclo vegetativo do girassol depende do genótipo e das condições climáticas como luz, temperatura e água, entre outros fatores.

Em experimentos, com a cultura do girassol, conduzidos por Thomas et al. (1982) foram observadas produtividades de 7,29 t/ha de MS. Gonçalves et al. (1996)

'Parte da Tese de Doutorado do primeiro autor, projeto parcialmente financiado pela FAPEMIG.

${ }^{2}$ Professor, DSc., Universidade de Alfenas/UNIFENAS - adauton.rezende@unifenas.br

${ }^{3}$ Professor, DSc., Titular do Departamento de Zootecnia/DZO - Universidade Federal de Lavras/UFLA - Cx. P. 3037 - $37200-000$ - Lavras, MG aricardo@ufla.br

${ }^{4}$ Aluno do curso de agronomia da Universidade de Alfenas/UNIFENAS - alexandrerv@nwnet.com.br

${ }^{5}$ Aluno do curso de zootecnia da Universidade Federal de Lavras/UFLA - Cx. P. 3037 - 37200-000 - Lavras, MG

${ }^{6}$ Mestrando da Universidade de Alfenas/UNIFENAS - h2vilela@yahoo.com.br 
obtiveram 8,55 t/ha de MS para plantio em fevereiro e corte com 103 dias; já Silva et al. (1998) registram produções de 7,82 e 10,76 t/ha de MS com estandes de 50.000 e 70.000 plantas/ha, respectivamente.

A concentração de MS do material a ser ensilado tem grande importância sobre a qualidade da silagem obtida porque influencia diretamente o padrão de fermentação do material ensilado (GONÇALVES et al., 1996).

Em trabalho realizado por Thomas et al. (1982), nos Estados Unidos da América, observou-se que o ponto ideal para ensilagem do girassol é quando mais de $75 \%$ dos grãos do capítulo estão maduros. Porém, em pesquisa no Brasil, quando o corte foi realizado dos 96 aos 110 dias da semeadura e com 50 a $75 \%$ dos grãos maduros, foram obtidas silagens com 21 a $25 \%$ de MS (CASTRO et al., 1996).

Tomich (1999) verificou, entre 13 cultivares, teores médios de proteína bruta $(\mathrm{PB})$ dos materiais originais e das silagens de 9,13 e $8,89 \%$, respectivamente, sendo que os valores máximo e mínimo ocorridos na silagem foram observados para os híbridos M 734 com 9,81\% e Rumbosol 91 com 7,23\%, respectivamente.

Almeida et al. (1995) encontraram, para silagens de milho, sorgo e girassol, valores de $\mathrm{pH}$ de $3,6,4,0$ e 3,5, respectivamente, e verificaram valores de fibra em detergente neutro (FDN) de 68,37; 71,35 e 65,88\%, respectivamente.

Lloveras (1990), comparando silagens de milho, sorgo e girassol, encontrou valores de digestibilidade "in vitro" da MS (DIVMS) para o milho, de 69,3\%; para o sorgo, de $56,4 \%$ e para o girassol, de $64,5 \%$. Esse autor relata, ainda, que a colheita das plantas de girassol para produção de silagem quando feita em estádio de maturação mais avançado interfere na digestibilidade da fibra devido à interferência da fração lipídica.

Realizou-se este estudo com o objetivo de avaliar o efeito da idade de corte de seis cultivares de girassol sobre o valor nutritivo das respectivas silagens.

\section{MATERIAL E MÉTODOS}

Os trabalhos foram conduzidos no Departamento de Zootecnia da Universidade Federal de Lavras - UFLA, Lavras, Minas Gerais. Segundo Castro Neto \& Silveira (1983), Lavras-MG situa-se a $21^{\circ} 14^{\prime}$ de latitude Sul e $45^{\circ}$ 00'de longitude Oeste de Greenwich, com uma altitude média de 918 metros. O clima da região é do tipo CWB, segundo a classificação de Köppen, sendo a precipitação máxima de verão maior ou igual a dez vezes a precipitação do mês mais seco, tendo ainda duas estações definidas: seca, de abril a setembro, e chuvosa, de outubro a março. A precipitação anual média é de $1471 \mathrm{~mm}$, com temperaturas médias das máximas e mínimas de 22,6 e $15,8^{\circ} \mathrm{C}$, respectivamente. A semeadura foi efetuada em 4 de novembro e os cortes realizados em fevereiro, quando foram observados valores mensais médios de temperatura de $22^{\circ} \mathrm{C}$, precipitação de $207,8 \mathrm{~mm}$ e umidade relativa do ar de $76 \%$.

$\mathrm{O}$ solo da área experimental fica situado na meia encosta de uma vertente de topografia ondulada (declividade entre 12 e 18\%), cuja cobertura pedológica é um Latossolo Vermelho Amarelo distrófico, de fertilidade baixa a moderada e textura muito argilosa.

As análises químicas da amostra do solo utilizado no experimento foram efetuadas no Laboratório de Fertilidade do Solo da UFLA, cujos resultados são apresentados na Tabela 1 .

A calagem e as adubações foram feitas com base nas exigências da cultura, segundo a Comissão de Fertilidade do Solo do Estado de Minas Gerais (CFSEMG, 1999), e nos resultados da análise química do solo. Para elevar o índice de saturação por bases a $70 \%$ foi aplicada, antes da aração, 0,8 t/ha de calcário dolomítico com PRNT igual a $80 \%$. A adubação mineral foi realizada aplicando-se no sulco, durante a semeadura, $300 \mathrm{~kg} / \mathrm{ha}$ da fórmula 8-28$16+\mathrm{Zn}$. Aos 40 dias após a semeadura foi feita a adubação de cobertura com aplicação de $30 \mathrm{~kg}$ de $\mathrm{N}$, via solo, e $1 \mathrm{~kg}$ de $\mathrm{B}$ e $1 \mathrm{~kg} \mathrm{Zn}$ por hectare, via foliar, tendo como fontes de nutrientes sulfato de amônio, ácido bórico e sulfato de zinco, respectivamente.

TABELA1 - Resultados da análise de solo da área experimental realizada em outubro/1998.

\begin{tabular}{|c|c|c|c|c|c|c|c|c|c|c|c|}
\hline \multirow{2}{*}{ Camada $(\mathrm{cm})$} & \multirow{2}{*}{ pH } & \multirow{2}{*}{$P\left(\mathrm{mg} / \mathrm{dm}^{3}\right)$} & $\mathbf{K}$ & $\mathbf{C a}$ & Mg & Al & $\mathbf{H}$ & $\mathbf{S}$ & $\mathbf{T}$ & $\mathbf{V}$ & \multirow{2}{*}{$\begin{array}{c}\text { MO } \\
\text { dag/kg }\end{array}$} \\
\hline & & & \multicolumn{7}{|c|}{$\mathrm{cmol} / \mathrm{dm}^{3}$} & $(\%)$ & \\
\hline \multirow[t]{3}{*}{0 a 20} & 5,9 & 3,0 & 0,50 & 1,8 & 1,10 & 0,0 & 2,3 & 3,0 & 5,3 & 55,6 & 3,1 \\
\hline & \multicolumn{9}{|c|}{ Análise granulométrica } & & \\
\hline & \multicolumn{2}{|c|}{ Areia(g/kg) } & \multicolumn{4}{|c|}{ Silte $(\mathrm{g} / \mathrm{kg})$} & \multicolumn{3}{|c|}{ Argila (g/kg) } & \multicolumn{2}{|c|}{ Densidade $\left(\mathrm{t} / \mathrm{m}^{3}\right)$} \\
\hline 0 a 20 & \multicolumn{2}{|r|}{90} & \multicolumn{3}{|c|}{280} & & \multicolumn{3}{|c|}{630} & \multicolumn{2}{|c|}{1,0} \\
\hline
\end{tabular}


Foram utilizados os híbridos Cargill C 11, Braskalb DK 180, Braskalb DK 4040, Morgon M 92007, Morgon M 742 e a variedade V 2000 da Embrapa.

O delineamento experimental utilizado foi o de blocos casualizados com 4 repetições, em um esquema fatorial $2 \times 6$, sendo os fatores idade de corte e cultivares. A parcela experimental constou de 4 linhas de 5 metros de comprimento cada uma, espaçadas de $0,90 \mathrm{~m}$ sendo considerada como área útil as duas linhas centrais com área de $4,5 \mathrm{~m}^{2}$.

Os cortes foram realizados em duas épocas, a saber:

a) Aos 95 dias após a semeadura, quando a taça da inflorescência apresentava-se de cor amarelo-escura e as brácteas ainda verdes;

b) Aos 110 dias após a semeadura, quando as plantas encontravam-se completamente maduras, ou seja, amarelecidas.

As plantas foram picadas mecanicamente em partículas de 2,0 a 3,0 cm de tamanho. Após intensa homogeneização do material picado, parte foi pesada e ensilada em silos de laboratório, confeccionados com tubos de "PVC" de dez centímetros de diâmetro e quarenta centímetros de comprimento, de maneira a obter uma densidade de $600 \mathrm{~kg} / \mathrm{m}^{3}$.

Decorridos 30 dias os silos foram abertos. A parte superior de cada silo $(7 \mathrm{~cm})$ foi retirada e descartada. $\mathrm{O}$ material central do silo foi homogeneizado em bandejas de plástico, sendo as amostras coletadas e pesadas em sacos de papel, levadas para estufa de ventilação forçada com temperaturas de $60-65^{\circ} \mathrm{C}$, por 72 horas. As amostras présecas foram moídas em peneira de $1,0 \mathrm{~mm}$, colocadas em recipientes de polietileno com tampa, identificadas e armazenadas para posteriores análises.

As análises bromatológicas foram feitas no Laboratório de Nutrição Animal do Departamento de Zootecnia da UFLA, Lavras- MG.
No momento em que o silo foi aberto, $10,0 \mathrm{~g}$ da silagem foram imediatamente amostrados para avaliação do $\mathrm{pH}$, utilizando-se um potenciômetro Beckman Expandomatic SS-2, após a extração do suco de cada silagem.

As determinações de matéria seca (MS) a $105^{\circ} \mathrm{C}$, proteína bruta $(\mathrm{PB})$ e extrato etéreo (EE) foram realizadas conforme as técnicas da Association of Official Analytical Chemists, citado por Silva (1981). A determinação do nitrogênio $(\mathrm{N})$ foi feita pelo método micro-Kjeldahl. O teor de $\mathrm{N}$ multiplicado pelo fator 6,25 resultou no teor de $\mathrm{PB}$, que foi corrigido para MS. Quanto à análise de fibra em detergente neutro (FDN), seguiu-se a metodologia descrita por Goering \& Soest (1975). A análise estatística dos dados foi realizada utilizando-se o programa SISVAR (FERREIRA, 2000). Para comparação das médias, foi utilizado o teste de Scott-Knott a 5\%.

\section{RESULTADOS E DISCUSSÃO}

Comparando-se as produções médias de MS $(\mathrm{P}<0,05)$, observaram-se valores variando de 4,88 a 11,27 t/ ha para a variedade V 2000 e o híbrido M 92007, respectivamente, sendo que os demais híbridos apresentaram produções de MS intermediárias, com a média geral de 8,51 t/ha (Tabela 2).

As diferenças observadas nas produções de MS a favor dos híbridos, em relação à variedade V 2000, provavelmente possam ser atribuídas ao maior vigor genético dos híbridos e à maior tolerância às principais doenças do girassol. Além disso, deve-se considerar, ainda, os menores valores de altura e número de plantas da variedade V2000 obtidos nas idades de colheita, o que influenciou negativamente o rendimento.

TABELA 2 - Rendimento de matéria seca (t/ha) das cultivares de girassol em diferentes idades de corte.

\begin{tabular}{cccc}
\hline \multirow{2}{*}{ Cultivares } & \multicolumn{2}{c}{ Idade de corte (dias) } & Médias \\
\cline { 2 - 4 } M 92007 & $\mathbf{9 5}$ & $\mathbf{1 1 0}$ & $11,27 \mathrm{~A}$ \\
M 742 & 10,66 & 11,89 & $8,96 \mathrm{~B}$ \\
V 2000 & 8,37 & 9,55 & $4,88 \mathrm{C}$ \\
DK 180 & 4,37 & 5,40 & $8,13 \mathrm{~B}$ \\
DK 4040 & 7,72 & 8,54 & $8,97 \mathrm{~B}$ \\
C 11 & 8,90 & 9,04 & $8,87 \mathrm{~B}$ \\
\hline Médias & 8,82 & 8,92 & 8,51 \\
\hline
\end{tabular}

Médias seguidas de letras diferentes, minúsculas na linha e maiúsculas na coluna, diferem entre si ao nível de 5\% de probabilidade pelo teste de Scott-Knott.

Ciênc. agrotec., Lavras, v. 31, n. 3, p. 896-902, maio/jun., 2007 
De uma maneira geral, as produções de MS observadas na presente pesquisa foram superiores às encontradas em experimentos realizados por Tomich (1999), ao avaliar 13 cultivares com plantio em fevereiro, com produções mínima e máxima de 3,57 e 7,75 t/ha, respectivamente.

Os teores de MS elevaram-se $(p<0,05)$ simultaneamente à evolução fenológica do girassol, ocorrendo os maiores valores nas silagens elaboradas na segunda idade de corte, independente da cultivar (Tabela 3). Nesse estádio fenológico (R-9), as plantas se encontravam em maturação completa, com folhas e hastes secas e grãos duros.

Pesquisadores, como Castro et al. (1996), recomendam o corte em estádios mais avançados, próximos à maturidade fisiológica das sementes, quando aproximadamente $75 \%$ dos grãos encontram-se maduros.

Embora tivesse sido observada interação idade de corte $\mathrm{x}$ cultivar, de uma maneira geral os maiores valores de $\mathrm{pH}$ foram observados nas silagens provenientes de plantas colhidas na segunda idade de corte (Tabela 3). Isto sugere que, nas silagens confeccionadas na primeira idade de corte, provavelmente tenha ocorrido maior fermentação lática, propiciando queda mais intensa do $\mathrm{pH}$ e também pelo fato do teor de MS na segunda idade de corte ter sido mais elevado, limitando a fermentação pela alta osmolaridade do meio.

Como houve interação idade de corte $\mathrm{x}$ cultivar $(\mathrm{P}<0,05)$, o $\mathrm{pH}$ das silagens apresentou comportamento diferente entre as cultivares em cada idade de corte. $\mathrm{Na}$ primeira idade o maior valor de $\mathrm{pH}$ foi da cultivar V 2000, seguido pelos valores referentes às cultivares C 11, M 742, DK 4040, M 92007 e DK 180. No entanto, na segunda idade de corte, valores maiores de $\mathrm{pH}$ foram observados nas silagens das cultivares V 2000, M 92007 e M 742, as quais não diferiram entre si. A provável explicação para a inversão dos valores de $\mathrm{pH}$ nas silagens dos híbridos M 92007 e M 742 é que na segunda idade de corte as plantas desses se encontravam com altos valores de MS, propiciando, conseqüentemente, aumentos significativos nos valores de pH. Já com relação à variedade V 2000, os valores de MS das plantas já se encontravam altos na primeira idade de corte, uma vez que a mesma possui ciclo precoce.

Os valores de $\mathrm{pH}$ encontrados nas silagens de girassol na presente pesquisa foram similares aos encontrados por Tosi et al. (1975), de 4,4 a 5,56. Gonçalves et al. (2000) consideram altos os valores de $\mathrm{pH}$ encontrados nas silagens de girassol, comparando-as com as silagens de milho e sorgo. Os autores indicaram que esses valores podem ser atribuídos aos maiores teores protéicos do girassol, o que resulta em redução na taxa de açúcar/proteína e no poder tampão, a qual influencia sobremaneira o $\mathrm{pH}$ da silagem.

Nas silagens da cultivar M 742, correspondentes à segunda idade de corte, foram observados os menores teores de $\mathrm{PB}(\mathrm{P}<0,05)$, os quais não se diferenciaram dos observados para o cultivar M 92007 (Tabela 4).

De uma maneira geral, as concentrações médias de PB observadas nas silagens de girassol, na presente pesquisa, foram semelhantes àquelas observadas nas pesquisas desenvolvidas por Almeida et al. (1995), as quais variaram de 10,60 a 13,57\%.

Os teores de PB observados nesse trabalho estão acima do mínimo exigido, cujo valor é de $7 \%$ na dieta dos ruminantes, conforme relatado por Church (1988). O autor salienta, ainda, que esse valor está associado à melhor fermentação microbiana efetiva no rúmen dos animais.

TABELA 3 - Teores de matéria seca (MS) e valores de pH das silagens de girassol em função da idade de corte e de cultivares.

\begin{tabular}{lcccc}
\hline \multirow{2}{*}{ Cultivares } & \multicolumn{2}{c}{ MS (\%) } & \multicolumn{2}{c}{ Idade de Corte (dias) } \\
\cline { 2 - 4 } & \multicolumn{2}{c}{ Idade de Corte (dias) } & $\mathbf{1 1 0}$ & $\mathbf{9 5}$ \\
\hline M 92007 & $\mathbf{9 5}$ & $30,12 \mathrm{Ca}$ & $4,02 \mathrm{Cb}$ & $5,36 \mathrm{Aa}$ \\
M 742 & $21,85 \mathrm{Ab}$ & $34,08 \mathrm{Ca}$ & $4,30 \mathrm{Cb}$ & $5,32 \mathrm{Aa}$ \\
V 2000 & $24,05 \mathrm{Ab}$ & $72,86 \mathrm{Aa}$ & $4,68 \mathrm{Ab}$ & $5,42 \mathrm{Aa}$ \\
DK 180 & $25,70 \mathrm{Ab}$ & $43,79 \mathrm{Ba}$ & $3,99 \mathrm{Cb}$ & $5,12 \mathrm{Ba}$ \\
DK 4040 & $21,90 \mathrm{Ab}$ & $36,10 \mathrm{Ca}$ & $4,22 \mathrm{Cb}$ & $5,11 \mathrm{Ba}$ \\
C 11 & $20,89 \mathrm{Ab}$ & $47,81 \mathrm{Ba}$ & $4,49 \mathrm{Bb}$ & $5,12 \mathrm{Ba}$ \\
Médias & 22,69 & 44,04 & 4,31 & 5,24 \\
\hline
\end{tabular}

Médias seguidas de letras diferentes, minúscula na linha e maiúscula na coluna, diferem entre si ao nível de 5\% de probabilidade pelo teste de Scott-Knott. 
$\mathrm{Na}$ interação idade $\mathrm{x}$ cultivar, foi verificado aumento nos valores de FDN em silagens provenientes de plantas da cultivar C 11, com o aumento da idade de corte (Tabela 4). De acordo com Mertens (1982), o teor de FDN está altamente correlacionado com a idade da planta. À medida que as plantas avançam nos estádios fenológicos, ocorre redução dos conteúdos celulares e aumento na lignificação dos tecidos.

Pôde-se verificar na interação cultivar $\mathrm{x}$ idade (Tabela 4) que o maior valor de FDN referente à primeira idade de corte foi da cultivar M 92007, sendo que os valores de FDN das silagens das demais cultivares não se diferenciaram entre si $(\mathrm{P}>0,05)$. Entretanto, na segunda idade de corte, os valores de FDN das silagens referentes às cultivares M 92007, DK 4040 e C 11 foram superiores e não diferiram entre si.
Observou-se interação entre genótipo e idade de corte para os teores de EE das silagens (Tabela 5). Silagens das cultivares C 11, DK 180 e V 2000 apresentaram diminuição dos teores de EE com o avanço da idade. Isso provavelmente tenha ocorrido em decorrência da maior precocidade das plantas dessas cultivares, proporcionando contribuição maior dos grãos, mesmo na primeira idade de corte.

Ao estudar o efeito de genótipo dentro da idade de corte, observaram-se maiores valores de $\mathrm{EE}(\mathrm{P}<0,05)$ nas silagens das cultivares V 2000, DK 180, DK 4040 e C 11 na primeira idade de corte. Já para as cultivares $M$ 742, DK 4040, M 92007 e V 2000 os valores de EE foram maiores quando a ensilagem foi realizada em plantas com estádios mais avançados de maturação, ou seja, na segunda idade de corte.

TABELA 4 - Teores de proteína bruta (PB) e fibra em detergente neutro (FDN) das silagens de girassol em função da idade de corte e de cultivares.

\begin{tabular}{lcccc}
\hline \multirow{2}{*}{ Cultivares } & \multicolumn{2}{c}{ PB (\%) } & \multicolumn{2}{c}{ FDN (\%) } \\
\cline { 2 - 4 } & \multicolumn{2}{c}{ Idade de Corte (dias) } & $\mathbf{9 5}$ & Idade de Corte (dias) \\
\cline { 2 - 4 } & $\mathbf{9 5}$ & $11,21 \mathrm{Ca}$ & $58,28 \mathrm{Aa}$ & $56,80 \mathrm{Aa}$ \\
\hline M 92007 & $10,25 \mathrm{Cb}$ & $11,29 \mathrm{Cb}$ & $54,34 \mathrm{Ba}$ & $52,92 \mathrm{Ba}$ \\
M 742 & $12,72 \mathrm{Aa}$ & $13,56 \mathrm{Aa}$ & $53,25 \mathrm{Ba}$ & $51,65 \mathrm{Ba}$ \\
V 2000 & $11,03 \mathrm{Bb}$ & $12,39 \mathrm{Ba}$ & $53,87 \mathrm{Ba}$ & $54,50 \mathrm{Ba}$ \\
DK 180 & $11,03 \mathrm{Bb}$ & $12,64 \mathrm{Ba}$ & $54,07 \mathrm{Ba}$ & $55,54 \mathrm{Aa}$ \\
DK 4040 & $11,90 \mathrm{Ab}$ & $13,48 \mathrm{Aa}$ & $54,16 \mathrm{Bb}$ & $58,77 \mathrm{Aa}$ \\
C 11 & $10,26 \mathrm{Cb}$ & 12,43 & 54,65 & 55,03 \\
\hline Médias & 11,20 & &
\end{tabular}

Médias seguidas de letras diferentes, minúscula na linha e maiúscula na coluna, diferem entre si ao nível de 5\% de probabilidade pelo teste de Scott-Knott.

TABELA 5 - Concentrações de extrato etéreo (EE) e valores de digestibilidade "in vitro" da matéria seca (DIVMS) em função da idade de corte e cultivares.

\begin{tabular}{lcccc}
\hline \multirow{2}{*}{ Cultivares } & \multicolumn{2}{c}{ EE (\%) } & \multicolumn{2}{c}{ DIVMS(\%) } \\
\cline { 2 - 4 } & \multicolumn{2}{c}{ Idade de Corte (dias) } & \multicolumn{2}{c}{ Idade de Corte (dias) } \\
\cline { 2 - 4 } & $\mathbf{9 5}$ & $\mathbf{1 1 0}$ & $\mathbf{9 5}$ & $\mathbf{1 1 0}$ \\
\hline M 92007 & $13,10 \mathrm{Bb}$ & $14,68 \mathrm{Aa}$ & $42,00 \mathrm{Cb}$ \\
M 742 & $13,89 \mathrm{Bb}$ & $15,03 \mathrm{Aa}$ & $58,77 \mathrm{Aa}$ & $48,52 \mathrm{Ab}$ \\
V 2000 & $15,68 \mathrm{Aa}$ & $14,51 \mathrm{Ab}$ & $53,34 \mathrm{Ba}$ & $46,11 \mathrm{Bb}$ \\
DK 180 & $15,33 \mathrm{Aa}$ & $13,60 \mathrm{Bb}$ & $55,73 \mathrm{Ba}$ & $49,80 \mathrm{Ab}$ \\
DK 4040 & $14,97 \mathrm{Aa}$ & $14,97 \mathrm{Aa}$ & $59,88 \mathrm{Aa}$ & $50,77 \mathrm{Ab}$ \\
C 11 & $14,87 \mathrm{Aa}$ & $12,48 \mathrm{Cb}$ & $55,22 \mathrm{Ba}$ & $51,25 \mathrm{Ab}$ \\
Médias & 14,63 & 14,21 & 56,21 & 48,07 \\
\hline
\end{tabular}

Médias seguidas de letras diferentes, minúscula na linha e maiúscula na coluna, diferem entre si ao nível de $5 \%$ de probabilidade pelo teste de Scott-Knott.

Ciênc. agrotec., Lavras, v. 31, n. 3, p. 896-902, maio/jun., 2007 
Em vários trabalhos sobre composição bromatológica de silagem de girassol são relatados aumentos gradativos nos valores de EE a partir do início do florescimento até a maturação completa dos capítulos. Dentre esses, pode-se citar os de Câmara \& Monteiro (1999), que observaram aumento na concentração de EE de 11,8 para 18,88\% em silagens de plantas apresentando capítulo de cor amarela escura e as brácteas ainda verdes, e em estádio da maturidade fisiológica dos aquênios completamente madura, respectivamente.

Os menores valores de coeficientes de DIVMS foram verificados para as cultivares M 92007, V 2000, DK 180 e C 11, para a primeira idade de corte. Já na segunda idade, o menor valor foi observado para a cultivar M 92007, seguido da cultivar V 2000 (Tabela 5).

Independentemente do cultivar utilizado, os valores médios de DIVMS das silagens foram maiores quando a ensilagem foi realizada na primeira idade de corte $(56,21 \%)$, em relação aos observados na segunda idade $(48,07 \%)$. Esses resultados têm sido observados em trabalhos dessa natureza, uma vez que a colheita foi realizada em estádio de maturação mais avançado. Nesse caso, há maior interferência da fração lipídica e também dos carboidratos estruturais.

De acordo com Palmquist \& Jenkins (1980), o excesso de lipídeos na dieta promove o envelhecimento físico da fibra e impede o ataque microbiano, reduzindo a DIVMS. Nessa pesquisa, maiores valores de EE (Tabela 5) foram observados em silagens correspondentes à segunda idade de corte. Ao analisar os valores de DIVMS para essa mesma idade, os mesmos foram inferiores, mostrando, assim, a interferência do teor de EE na DIVMS.

\section{CONCLUSÕES}

$\mathrm{O}$ rendimento de forragem e as características bromatológicas do girassol são influenciados pelo genótipo e idade de corte, bem como pela interação desses fatores.

A fenologia das cultivares é fator fundamental para a determinação da idade de corte ideal, objetivando-se a maximização da produção e do valor nutritivo.

\section{REFERÊNCIAS BIBLIOGRÁFICAS}

ALMEIDA, M. F.; TIESENHAUSEN, I. M. E. V. von; AQUINO, L. H. Composição química e consumo voluntário das silagens de sorgo, em dois estádios de corte, girassol e milho para ruminantes. Ciência e Prática, Lavras, v. 19, n. 3, p. 315-321, 1995.
CÂMARA, S. M. S.; MONTEIRO, C. A. Desempenho vegetativo e reprodutivo de quatro cultivares de girassol (Helianthus annus L.) sob cinco densidades de plantas em época safrinha. Safra 1997. In: REUNIÃO NACIONAL DE PESQUISA DE GIRASSOL, 13.; SIMPÓSIO NACIONAL SOBRE A CULTURA DE GIRASSOL, 1999, Itumbiara. Anais... Londrina: Embrapa Soja, 1999. p. 121-122. (Documentos, 35).

CASTRO, C.; CASTIGLIONI, V. B. R.; BALLA, A. A cultura do girassol: tecnologia de produção. Goiânia: Embrapa/ CNPSo, 1996. $20 \mathrm{p}$.

CASTRO NETO, P.; SILVEIRA, J. V. Precipitação provável para Lavras-MG, baseada na função de distribuição de probabilidade gama III: períodos de 10 dias. Ciência e Prática, Lavras, v. 7, n. 1, p. 58-65, 1983.

CHURCH, D. C. The ruminant animal digestive physiology and nutrition. New Jersey: Prentice Hall, 1988. 564 p.

COMISSÃO DE FERTILIDADE DO SOLO DO ESTADO DE MINAS GERAIS. Recomendação do uso de corretivos e fertilizantes em Minas Gerais: $5^{\mathrm{a}}$ aproximação. Viçosa, 1999. $359 \mathrm{p}$.

FERREIRA, D. F. Análises estatísticas por meio do Sisvar para windows versão 4.0. In: REUNIÃO ANUAL DA REGIÃO BRASILEIRA DA SOCIEDADE INTERNACIONAL DE BIOMETRIA, 45., 2000, São Carlos, SP. Anais... São Carlos: UFSCAR, 2000. p. 255-258.

GOERING, H. K.; SOEST, P. J. van. Forage fiber analysis: apparatus, reagents, procedures, and some applications. Washington: [s.n.], 1975. (Agricultural Handbook, 379).

GONÇALVES, L. C.; SILVA, F. F.; CORREA, C. E. S. Produtividade e teor de matéria seca de girassol (Helianthus annus L.) cultivado em diferentes épocas do ano e colhido em diferentes estágios vegetativos. In: REUNIÃO ANUAL SOCIEDADE BRASILEIRA DE ZOOTECNIA, 33., 1996, Fortaleza. Anais... Fortaleza: SBZ, 1996.

GONÇALVES, L. C.; TOMICH, T. R.; PEREIRA, L. G. R. Produção e utilização de silagem de girassol (Helianthus annus L.). In: SIMPÓSIO DE FORRAGICULTURA E PASTAGENS: TEMAS EM EVIDÊNCIA, 1., 2000, Lavras, MG. Anais... Lavras: UFLA, 2000. p. 203-235. 
LLOVERAS, J. Dry matter yield and nutritive value of four summer annual crops in north-weast Spain (Galicia). Grass and Forage Science, Oxford, v. 45, n. 3, p. 243-248, 1990.

MERTENS, D. R. Using neutral detergent fiber to formulate dairy rations. Athens: University of Georgia, 1982.

PALMQUIST, D. L.; JENKINS, T. C. Fat in lactation rations: review. Journal of Dairy Science, Champaign, v. 63, n. 1, p. 1-14, 1980.

SILVA, A. W. L.; MACEDO, A. F.; HOESCHL NETO, W. Efeito da densidade de semeadura sobre a produtividade $\mathrm{e}$ composição bromatológica de silagens de girassol. In: REUNIÃO ANUAL DA SOCIEDADE BRASILEIRA DE ZOOTECNIA, 35., 1998, Botucatu. Anais... Botucatu: SBZ, 1998. p. 635-637.
SILVA, D. J. Análise de alimentos: métodos químicos e biológicos. Viçosa: UFV, 1981. 160 p.

THOMAS, V. M.; MURRAY, G. A.; TACKER, D. L. Sunflower silage in rations for lactantig Holsteins cows. Journal of Dairy Science, Champaign, v. 65, n. 2, p. $267-$ $270,1982$.

TOMICH, T. R. Avaliação do potencial forrageiro e das silagens de treze cultivares de girassol (Helianthus annus L.). 1999. 131 f. Dissertação (Mestado em Zootecnia) Universidade Federal de Minas Gerais, Belo Horizonte, 1999.

TOSI, H.; SILVEIRA, A. C.; FARIA, V. P. Avaliação do girassol (Helianthus annus L.) como planta para ensilagem. Revista da Sociedade Brasileira de Zootecnia, Viçosa, v. 4, n. 1, p. 39-48, 1975. 